Wezel, N. van, Francke, A.L., Acun, E.K., Devillé, W.L.J.M., Grondelle, N.J. van, Blom, M.M.

Explanatory models and openness about dementia in migrant communities: a qualitative study among

female family carers. Dementia: International Journal of Social Research and Practice: 2016

\begin{tabular}{|l|l|}
$\begin{array}{l}\text { Postprint } \\
\text { Version }\end{array}$ & 1.0 \\
\hline $\begin{array}{l}\text { Journal website } \\
\text { Pubmed link }\end{array}$ & http://dem.sagepub.com/content/early/2016/06/15/1471301216655236.long \\
\hline DOI & http://www.ncbi.nlm.nih.gov/pubmed/27306963 \\
\hline nivel
\end{tabular}

This is a NIVEL certified Post Print, more info at http://www.nivel.eu

\title{
Explanatory models and openness about dementia in migrant communities: A qualitative study among female family carers
}

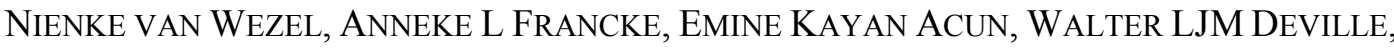 \\ NIES J VAN GRONDELLE, MARCO M BLOM
}

\begin{abstract}
Background The prevalence of dementia is increasing among people with a Turkish, Moroccan and Surinamese-Creole background. Because informal care is very important in these communities, it is pertinent to see what explanations female family carers have for dementia and whether they can discuss dementia openly within the community and the family.

Method Forty-one individual interviews and six focus group interviews $(\mathrm{n}=28)$ were held with female Turkish, Moroccan and Surinamese Creole family carers who are looking after a close relative with dementia, and who live in The Netherlands. Qualitative analysis has been carried out, supported by the software MaxQda.

Results The dominant explanations of dementia given by the female family carers interviewed are in line with what Downs et al. describe as the explanatory models 'dementia as a normal ageing process' and 'dementia as a spiritual experience'. In addition, some female family carers gave explanations that were about an interplay between various factors. Turkish and Moroccan informal caregivers ascribe the causes of dementia relatively often to life events or personality traits, whereas Surinamese Creole caregivers frequently mention physical aspects, such as past dehydration. However, the explanatory model 'dementia as a neuropsychiatric condition', which is dominant in Western cultures, was rarely expressed by the informal caregivers. The female family carers generally talked openly about the dementia with their close family, whereas particularly in the Turkish and Moroccan communities open communication within the broader communities was often hampered, e.g. by feelings of shame.

Conclusions Female family carers of Turkish, Moroccan or Surinamese Creole backgrounds often consider dementia as a natural consequence of ageing, as a spiritual experience, and/or as an interplay between various factors. They feel
\end{abstract}


Wezel, N. van, Francke, A.L., Acun, E.K., Devillé, W.L.J.M., Grondelle, N.J. van, Blom, M.M. Explanatory models and openness about dementia in migrant communities: a qualitative study among

female family carers. Dementia: International Journal of Social Research and Practice: 2016

they can talk openly about dementia within their close family, while outside the $<>$ close family this is often more difficult.

\section{INTRODUCTION}

Dementia among populations with a non-western background is a topical issue. The ageing population and increasing life expectancy are leading to significant increases in the number of people with dementia in industrialized countries (Alzheimer's Disease International (ADI), 2012). This also applies to non-Western communities in those countries (Demirovic et al., 2003; Fitzpatrick et al., 2004). In the Netherlands, for instance, it is estimated that about 28,000 people with a non-western background have dementia, which is $10 \%$ of the total number of patients. It is expected that this figure will have risen to about 38,000 (p34\%) by 2020, after which the increase will continue further due to the increased life expectancy and ageing of non-western minority groups (Alzheimer Nederland, 2013).

The increase in dementia will in fact be relatively greater among these groups than in the indigenous population, because illnesses such as diabetes and cardiovascular disease (which increase the risk of dementia) are more prevalent among people from non-western origin (Adelman, Blanchard, \& Livingstone, 2009; Dijkstra, Berghout, \& Sauerwein, 2003; Forouhi et al., 2006; Denktas et al., 2009).

The rise of dementia will place heavy demands on informal caregivers. Family-based care given by women is relatively common in non-western communities in The Netherlands, e.g. communities of people with a Turkish, Moroccan or Surinamese background. This is related to the importance placed there on care by close female family members, as well as barriers in the access to professional care (De Graaff, Francke, van den Muijsenbergh, \& Van der Geest, 2010; Denktas, 2011; van Wezel et al., 2014). Because of the increasing number of people with dementia and the fact that female family carers have an important role, it is relevant to explore what explanations those family carers have for dementia and the extent to which it is possible for them to discuss dementia openly within the community and the family.

Medical, gerontological and anthropological literature describes a variety of explanatory models regarding the cause of illness (e.g. Botsford, Clarke, \& Gibb, 2011; Cohen, 1992; Downs, Clare, \& Mackenzie, 2006; Kleinman, 1976; Sun, Ong, \& Burnette, 2012).

Explanatory models of illness in contemporary Western societies are largely framed within a medical model, where the causes of illness are sought in biological alterations in individuals (Crossley, 2000). However, the medical model is challenged by the biopsychosocial model (Engel, 1997). This model allows for an integration of the psychological and social aspects of illness alongside the purely biological aspects (Marks, Murray, Evans, \& Estacio, 2005).

Downs et al. (2006) described explanatory models of dementia in particular. They determine four explanatory models: dementia as a neuropsychiatric condition (which fits with the aforementioned medical model), dementia as a form of interplay between biological, psychological and social factors (which fits with the biopsychosocial model), dementia as a spiritual experience, and dementia as a normal ageing process. 
Wezel, N. van, Francke, A.L., Acun, E.K., Devillé, W.L.J.M., Grondelle, N.J. van, Blom, M.M. Explanatory models and openness about dementia in migrant communities: a qualitative study among

female family carers. Dementia: International Journal of Social Research and Practice: 2016

People who explain dementia as a normal ageing process, see the memory and behavioural problems of people with dementia as inherent of ageing. This way ofive looking at dementia is, according to Byetheway (1994), to be found above all in nonwestern groups in which being old is respected and the elderly are treated with respect. Other studies also indicate that nonwestern dementia caregivers often incorporate non-medical terms into their explanations of dementia (Botsford et al., 2011; Hinton, Franz, Yeo, \& Levkoff, 2005; Zhan, 2004).

Within the model of dementia as a spiritual experience, dementia is seen as a consequence of the effects of good spiritual influences, or often also of evil ones (the 'evil eye' or 'witchcraft', for instance). Spiritual forces are also thought to underpin the changes in behaviour or 'madness' of the person with dementia. Ascribing dementia to spiritual forces is seen primarily in non-Western cultures (Downs et al., 2006; Hussain, 2001).

The explanatory model that considers dementia as a neuropsychiatric condition sees dementia as a progressive brain disorder, generally Alzheimer's disease or vascular dementia, or both. Cognitive and behavioural changes that are associated with dementia are described in this model - which is dominant in Western cultures (Ayalon \& Arean, 2004; Hinton et al., 2005; Roberts et al., 2003) - as 'symptoms'. Seeing dementia as an interplay of factors is an explanatory model that is also quite common in Western cultures. People who work from this model (e.g. Kitwood, 1990) see dementia as an interaction between brain disorders (such as Alzheimer's disease) and psychosocial environmental factors. Downs et al. (2006) do point out here that the four explanatory models are not entirely mutually exclusive: different explanatory models can coexist within a single person, let alone any given community.

Next to describing the explanatory models that Turkish, Moroccan and SurinameseCreole female family carers use for dementia, we look at how openly the subject of dementia can be discussed in the communities concerned; this can also depend in part on the explanatory models that people have adopted for the illness. Studies among non-Western minorities in the US (Gary, 2005), Great Britain (Wolff, Pathare, Craig, \& Leff, 1996), Greece (Papadopulos, Leavey, \& Vincent, 2002) and the Netherlands (De Vries, 2009; Rijkers, 2010) show taboos against speaking openly about dementia. For instance, in Moroccan-Dutch communities, denial, shame and the emotions that come hand in hand with dementia keep the subject taboo (Rijkers, 2010). Dementia would also hardly discussed at all in Turkish-Dutch non-western communities; this is thought to be associated with fear of the condition as well as feelings of shame (De Vries, 2009). Finally, 'public stigma' (social groups endorsing stereotypes against a stigmatised group, in this case people with dementia) would hamper open discussions on dementia (Corrigan \& Watson, 2002; Graham et al., 2003; Werner \& Heinik, 2008).

The majority of the studies mentioned above (De Vries, 2009; Rijkers, 2010) only examine the perspectives of a single group. Comparisons are however interesting, because it seems likely that explanations chosen for dementia and how freely it can be discussed, varies between different non-western groups. Therefore this qualitative study gives insights into the differences and similarities in the explanations for dementia and how freely this illness can be discussed, from the perspectives of female family carers from the three largest non- Western communities in the Netherlands (Turkish, Moroccan and Surinamese Creole). 
Wezel, N. van, Francke, A.L., Acun, E.K., Devillé, W.L.J.M., Grondelle, N.J. van, Blom, M.M. Explanatory models and openness about dementia in migrant communities: a qualitative study among

female family carers. Dementia: International Journal of Social Research and Practice: 2016

These insights can be used to tailor information and support for these non-western groups that are increasingly faced with dementia.

The following research questions are central to this study: (1) How do female family carers with a Turkish, Moroccan or Surinamese Creole background and who are living in The Netherlands explain and describe the dementia of their close relatives'?

(2) a. Do they perceive that their close relatives' dementia can be discussed openly within the family or in the wider community? $b$. Do they think that it is important to be able to discuss dementia openly? (3) What similarities and differences are there between female family carers with Turkish, Moroccan and Surinamese Creole backgrounds in terms of how openly dementia can be discussed and regarding the explanations of dementia? We use the term 'family carers' for people who voluntarily provide unpaid care for people in their family or social network. Family carers are for example partners, children or other close relatives who look after someone from their family or wider network.

The description as having a 'Turkish, Moroccan or Surinamese Creole background' refers in this case to people who are resident in the Netherlands but were themselves born in Turkey, Morocco or Suriname, or who have at least one parent who was born in one of those countries. The indicator 'Creole' appended to 'Surinamese' is used to refer to people who are at least partly of African descent. The Creole culture is a melting pot of various African cultures plus Indian and European influences; the religion is predominantly Christian and the mother tongue is Dutch. The first generation of Surinamese Creoles came to the Netherlands in the sixties or seventies to study, or as a consequence of decolonialization (Suriname used to be a Dutch colony).

The migration history of Turkish and Moroccans is different: the first migrants arrived in the Netherlands between 1965 and 1980 to work, or as family members of these so-called 'guest workers'. Although Turkish and Moroccans living in The Netherlands have differing ethnic backgrounds, there are overlaps, not only in their migration history, but also in terms of socio-economic status (generally low), religion (mostly Muslim) and mastery of Dutch (often poor among the first generation).

\section{METHOD}

\section{Choosing to do a qualitative study from the emic perspective of family caregivers}

We opted for qualitative research (individual interviews and focus group interviews) because we wanted to gain insights into individuals' own experiences and opinions. In our research, we focused on describing the 'emic perspective' (Headland, Pike, \& Harris, 1990; Reis, van der Geest, \& Gerrits, 2008), which in this case implies that we obtained a picture of how the Turkish, Moroccan and Surinamese-Creole female family carers themselves explain dementia and how openly it can be discussed within their own cultural and social context.

We focused on this emic view of family carers because of our special interest in this target group. Our research strategy can be characterized as a 'generic qualitative approach'. Generic qualitative research does not have a guiding set of philosophic assumptions or methodological strategies from one specific qualitative methodology, but exhibits some characteristics of various methodologies (such as grounded theory methodology or ethnography). Basic requirements of a generic qualitative approach are noting the researchers' position, congruence between methods and methodology, 
Wezel, N. van, Francke, A.L., Acun, E.K., Devillé, W.L.J.M., Grondelle, N.J. van, Blom, M.M. Explanatory models and openness about dementia in migrant communities: a qualitative study among

female family carers. Dementia: International Journal of Social Research and Practice: 2016

making explicit the approach to rigour, and identifying the researchers "analytic lens"' (Caelli, Ray, \& Mill, 2003).

\section{Recruitment and sampling for the individual interviews}

During the period from April 2010 to March 2011, semi-structured interviews were held with female family carers who were looking after a close relative with dementia or - where there was no official diagnosis (yet) - severe memory problems.

A total of 16 Turkish, 14 Moroccan and 11 Surinamese Creole female informal caregivers were interviewed. These women were recruited indirectly through nursing staff, dementia case managers, key figures from the ethnic communities or dementia educators. The recruitment process attempted to achieve some degree of spread in age and between the three groups involved. No minimum or maximum number of interviews was defined beforehand. A total of 41 individual interviews turned out to be sufficient to achieve data saturation in each of the three groupings, i.e. the point at which no more new or relevant information was being found when additional data was collected (Guest, Bunce, \& Johnson, 2006). Table 1 shows the backgrounds of the female family carers interviewed.

\section{Recruitment and sampling for the focus group interviews}

Focus group interviews were held in the period from May 2012 to July 2012, so that we could further refine the insights obtained from the preceding individual interviews. Six focus group interviews were held: two with Turkish female family carers, two with Surinamese Creole and two with Moroccan. Two to seven caregivers took part in each of the focus groups. A total of ten Turkish, six Surinamese Creole and twelve Moroccan carers participated in the focus group interviews (see Table 1). The recruitment of the participants for the focus groups was also done via care providers (nursing staff, case managers), key figures from the community and dementia educators with the same ethnic origins. Carers were only allowed to take part in a focus group interview if they had not yet been interviewed individually.

\section{Organization and content of the individual and focus group interviews}

Both the individual interviews and the focus group interviews worked with a list of topics and open questions, such as "Why are you able or not able to talk openly about the illness of your close relative within your family?", "A Are you able to talk about it openly within your community or not?" and "How would you explain how the illness arose in your relative?',

\section{[TABLE 1]}

These topic list questions were drawn up after discussions with experts of Dutch, Turkish, Moroccan and Surinamese origins and after studying the relevant literature (De Graaff \& Francke, 2003, 2010; Downs et al., 2006; Rijkers, 2010; Uiters, Deville, Foets, \& Groenewegen, 2006).

The individual interviews were held by the first author (NvW, a female native Dutch researcher and gerontologist, employed by Alzheimer Nederland), the third author (EK, a female Turkish/Dutch health scientist employed by Alzheimer Nederland) or by trained female interviewers with the same non-western backgrounds as the interviewees. The individual interviews were all held at the participants' homes. The interviews were held in Dutch, except for six of the Turkish family carers, whose mastery of Dutch was insufficient. 
Wezel, N. van, Francke, A.L., Acun, E.K., Devillé, W.L.J.M., Grondelle, N.J. van, Blom, M.M. Explanatory models and openness about dementia in migrant communities: a qualitative study among

female family carers. Dementia: International Journal of Social Research and Practice: 2016

These six interviews in Turkish were then translated literally into Dutch by the third 7 author (EK), whose mother tongue is Turkish but also speaks fluent Dutch. The nivel interviews took between one and two hours.

The six focus group interviews were held by the third author (EK), the fifth author (NvG, a female native Dutch health scientist who works as a project leader at Pharos, a knowledge and advice centre for healthcare for immigrants and refugees) or by trained interviewers with the same non-western background as those taking part. The focus group interviews were held in social centres, community centres and nursing and care homes. One focus group interview was held in Turkish and one in Arabic; the other four focus group interviews were in Dutch. The focus group interviews lasted between two and three hours.

\section{Analysis of the data from the individual interviews and focus group interviews}

In the initial phases of the analyses of the individual and focus group interviews open, inductive qualitative analyses were performed, within a cyclic process of data collection, analysis, additional data collection, et cetera. After each interview, the audio recording was typed out and the interview transcripts were read a number of times. Based on the interviews' content and sticking closely to the statements made by the interviewees, codes were assigned to interview fragments. Examples of these codes are 'shame', 'fear' 'life experience', 'normal aging' and 'openness'. In the final analyses stages, we also analysed deductively, using the concepts of explanatory models. The process of ordering and coding was assisted by MaxQda, a software program designed for computer-assisted qualitative data analysis (www.maxqda.com).

The first author analysed all the individual and focus group interviews. To improve the quality of the analyses and to prevent biased interpretation of the data, a main part of the interviews (all six focus group interviews and ten individual interviews) were independently analysed by at least one of the co-authors. The selected ten interviews were chosen because they contained much information. After the independent analysis, the results were compared and discussed with each other. Codes that are related to one another in terms of content were categorised in the final phase of the analyses, which led to the final themes presented in the Results section. The results of the analyses were checked by the trained interviewers with the same non-western background as the participants. They considered the representations of the carer's perspectives accurate.

The qualitative analyses revealed several themes, which are partially described in this paper. In another paper we described the informal carers' perspectives on caring for a loved one with dementia (van Wezel et al., 2014).

\section{Ethics statement}

All participants gave both written and verbal consent at the beginning of the individual or focus group interview. Verbal consent was also noted, partly because particularly the Moroccan and Turkish participants are more likely to have difficulty reading and writing in the Dutch language, which may possibly have meant they would just put a random scribble on the written declaration of consent. After the study was completed, the audio recordings were destroyed.

Since in this interview study only competent subjects were involved and the interviews did not involve any actions or interventions imposed to the participants, no approval by an ethics committee was required (according to the Dutch Medical Research Involving Human Subjects Act, see ccmo-online.nl). 
Wezel, N. van, Francke, A.L., Acun, E.K., Devillé, W.L.J.M., Grondelle, N.J. van, Blom, M.M. Explanatory models and openness about dementia in migrant communities: a qualitative study among

female family carers. Dementia: International Journal of Social Research and Practice: 2016

\section{RESULTS}

\section{Explanatory models}

In this study, the female family carers gave various explanations for how dementia had arisen in their close relative. The majority gave explanations that were in line with the explanatory model of 'dementia as a normal ageing process'. These caregivers saw the appearance of dementia in their relatives as something that they had no influence over and which was a logical consequence of natural ageing. When caregivers were asked about the 'first signs' or when they were asked if they knew the term 'dementia', they mostly referred to forgetfulness and mental deterioration. The terms 'dementia' and 'Alzheimer' were generally not used, despite the fact that most of the relatives concerned had already been formally diagnosed with dementia. The caregivers interviewed often referred to dementia as 'the forgetfulness disease' or just 'forgetfulness' for short. Other terms used were 'bunamak' or 'demans' (by Turkish informal caregivers) and 'kindsie' or 'kindsheid' (literally childishness, by Surinamese caregivers). These latter terms were explained by saying "when you get really old, it's like you're becoming a child again'”.

What I understand by 'dementia' is that you forget things, that you forget the structure - you lose the structure of your daily life. That you keep repeating things. Your purpose in life, what people expect of you, what you will be doing tomorrow you don't know these things any more.

Losing track of things in your head - that's dementia." (Turkish focus group interview) Another word that's often used is 'kindsie'. You go back to being a kid. They say that in Suriname too: you can be a child twice, but you only grow up once. You're born a child, you grow up, and then you become a child again. (Surinamese focus group interview) In addition, other family carers gave explanations that were about an interplay between life events, personality traits, and social and psychological factors. In this context, caregivers stated for example that their relative with dementia had had a very tough life, with depression or divorce, a great deal of reflection and worry and 'awkward' personality traits.

Prior physical problems or medication use were also given as explanations of dementia, often combined with life events and personality traits. Dehydration, sexually transmitted diseases or incorrect use of medication were often listed in this context, for example.

Yes, my father was always ... he fretted about things a lot, thinks about things a lot, so maybe he does simply have problems with his brain. He also has trouble sleeping, for instance, he suffers from insomnia and he's always had lots of sleeping pills for that. So yes, maybe that did play a part, him having to take so many sleeping pills because he was always staying awake and thinking about things. (Moroccan, individual interview) Why do you think that your mother-in-law has memory problems? Like I said earlier, she was always busy, she worshipped money - still does, even now that she's sick, but she's got no idea when to put her purse to one side. Her bank card, her handbag - all that money robbed her of her common sense. All I know is that she worships money. She didn't like anybody much, not even her own kids; she loved money. That's what caused it. (Turkish, individual interview) Um, the way I explain it - and it's what the doctor thought too, and I read about it as well then - is that dementia can occur suddenly in old people if they get dehydrated. And I think, because we saw it then, is that my mother really . . it was as if she 
Wezel, N. van, Francke, A.L., Acun, E.K., Devillé, W.L.J.M., Grondelle, N.J. van, Blom, M.M. Explanatory models and openness about dementia in migrant communities: a qualitative study among

female family carers. Dementia: International Journal of Social Research and Practice: 2016

suddenly went blank, and then when they've gone blank like that you really see fhat 7 something has happened in the brain. It's all down to the dehydration. (Surinamesiqvel Creole, individual interview) It is noticeable here that Turkish and Moroccan family carers ascribe the causes of dementia relatively often to non-physical aspects, such as having had a difficult life or personality traits, whereas Surinamese Creole caregivers mention physical aspects, such as dehydration and sexually transmitted diseases relatively often. When physical aspects were mentioned as explanations for dementia, these were often not sought in brain disorders such as Alzheimer's disease or vascular dementia.

Furthermore, the family carers interviewed also included a number - all of whom were relatively old Moroccan caregivers - who gave spiritual explanations for their relative's dementia: they saw their family member's dementia as a kind of 'possession' or 'magic' that God could cure. Various caregivers from the Moroccan and Turkish communities also stated that ascribing dementia to punishment by God or seeing it as a form of 'possession' was generally commonplace among more elderly firstgeneration Turks and Moroccans.

Somebody from the home care services comes and reads to him from the Koran about black magic. It's by no means certain that the cause of dementia isn't medical. There could still be hope. Hope that God will bestow his blessing after all and cast out the evil from him.

(Moroccan, individual interview) A lot of older people don't know what Alzheimer's or dementia are - they just don't know. They can't name it, or they confuse it with getting old or being possessed or black magic. They go looking for it in the alternative spiritual side of things, as it were. (Moroccan, individual interview)

\section{Openness about dementia within the close family}

The Turkish, Moroccan and Surinamese Creole family carers who were interviewed stated that the illness of their family member (usually a parent or parent-in-law) could in principle be discussed openly with sisters, sisters-in-law, brothers or other very close family.

I can talk easily enough about dementia. It isn't something that you have to hide. We talk about it within the family too, particularly because we want to help each other. (Turkish focus group interview) When talking about the subject with close family sometimes did become difficult was when it involved the problem of accepting the diagnosis and the grief that this engendered. The immediate family would sometimes refuse to believe it during the initial stages of the disease; they did not yet accept that their family member had dementia and thought that it was just fatigue or ordinary symptoms of ageing.

Problems discussing the matter openly with close family members were mostly restricted to the initial stages of the condition.

Whether or not it could be discussed with the person who had dementia depended largely on how they themselves viewed it. Informal caregivers sometimes found it awkward or impossible to talk to the person with dementia about their state of health. This was particularly true when that person did not recognize or acknowledge the disease themselves. In order to protect the close relative with dementia and avoid creating additional unrest, the subject was sometimes not discussed with that relative. In other cases, the relatives with dementia were themselves open about it and the family could therefore talk freely about it. 
Wezel, N. van, Francke, A.L., Acun, E.K., Devillé, W.L.J.M., Grondelle, N.J. van, Blom, M.M. Explanatory models and openness about dementia in migrant communities: a qualitative study among

female family carers. Dementia: International Journal of Social Research and Practice: 2016

We are not at all ashamed about it, but that's more because of the attitude of my parents themselves. They acknowledge it is happening. If my mother were to adpptve an attitude showing she was ashamed, then I might have responded differently too. But she says it easily enough, and she makes talking about it possible. And then so do I. (Turkish focus group interview)

\section{Denial, shame and uneasiness within the broader community}

Among Moroccan and Turkish family carers, it often seemed less easy to discuss the disease within the wider family and/or the community than it was within the immediate family.

Turkish and Moroccan family carers sometimes experienced disbelief and denial from e.g.

uncles, aunts or others from their community ("she's just old"), which caused distress among the caregivers and made them feel they were not being understood. Well, my other family members don't believe that my mother is forgetful or that she's got a condition - they simply don't believe it. And if they do notice her repeating what she says or notice things in her behaviour, then ... well, they laugh about it and forget it, because they don't want to acknowledge it. They're more likely to think, well she's old, she's just old, she's a bit nutty . . . literally 'crazy'. . . they say she's old and crazy. And well, they ignore her in fact too.

(Moroccan, individual interview) The reasons given for this were unfamiliarity with the disease and the associated fear and discomfort (particularly among older members of the community). The physical deterioration could be discussed, but talking about mental deterioration in particular went hand in hand with unease and reticence. People from the community did not inquire any further if the informal caregiver talked about their family member's condition, which left the caregivers feeling that there was no real interaction or depth in the conversation.

But my mother does say it, if they ask how she is doing. She say, well, it's not only physical - my head doesn't work like it should any more either. And then I think, oh, it's very good that she says it - she's aware of what's happening. Because that's the worst thing about it: your memory.

And then you see that it's very straightforward if you say I've got headaches or a pain in my stomach, but very awkward if you say that your mother is getting very forgetful. Then they really don't know what to say - oh, isn't that awful, yes, but they don't really dare to talk about it properly. It's new for them, it really is new. (Moroccan, individual interview) I can talk about it freely with the second generation, and with my mother-in-law as well, and with her family, with her brothers. But I do notice for instance if I talk about it with my own parents, my father gets very ... he's very quick to empathize with others and he finds its very difficult . .. I think my father finds it extremely uncomfortable to see my father-in-law like that.

Maybe he associates it with the thought that he might end up like that too; he has a great deal of difficulty with it, he forces himself to come round and visit, in fact ... but it keeps him awake at night after he's been round. (Turkish, individual interview) Some informal caregivers point out that in Turkish and Moroccan communities a 'culture of shame' and a 'culture of silence' exist, which affect the limited openness for such discussions within the wider community. Shame about dementia was 'shame about the disease', as well as 'shame about the behaviour of the person with dementia'. Within the Turkish and Moroccan communities, shame was also 
Wezel, N. van, Francke, A.L., Acun, E.K., Devillé, W.L.J.M., Grondelle, N.J. van, Blom, M.M. Explanatory models and openness about dementia in migrant communities: a qualitative study among

female family carers. Dementia: International Journal of Social Research and Practice: 2016

associated with the fact that the person with dementia was also sometimes seen $<>$ within the community as being 'crazy'.

nivel

I don't feel ashamed about it personally, but I can understand why other Turks might. In our culture, it is important what other people say and think about you. We feel for other people a lot, actually. People do get bothered about gossip and rumours, or that they might say weird things about your parents or family. Maybe it has something to do with that. (Turkish focus group interview) In the Moroccan community, people don't talk about dementia. There are people who think that somebody with dementia has gone mad. That they're round the bend. Gone a bit nutty. They don't think that the person is sick and has become forgetful; the label they put on them is 'mad', as if they did the same things but didn't have dementia. They're ashamed of it.

(Moroccan, focus group interview)

There was also shame amongst the immediate family about the changed behaviour that their family member sometimes showed, which the community might start gossiping about. It was not possible to see that anything was wrong from the outward appearance of their family member with dementia. That meant that the family carers felt there was not much empathy from the community for the behavioural changes of the person with dementia. In those situations, the family carers got a feeling that they had to justify the patient's behaviour to the surrounding community. However, the person suffering from dementia often did not want the community at large to know that they had this disease. Family carers were therefore unable to offer an explanation for the behaviour of their family member and felt ashamed or at lease 'uncomfortable', also because of the fact that people in the community thought that their relative had 'gone mad'.

Within the Surinamese Creole community, the family carers who were interviewed came up against little or no denial, shame or unease when talking about their relative's dementia with others from their community.

I don't come across people who don't want to talk about dementia, or who - shall we say - don't want to be open about it and want to keep it hidden. We are . . I think that our people are open and honest about it. And when I say 'our people', I mean the Surinamese community.

(Surinamese focus group interview) Compared with the Turkish and Moroccan communities, it was also possible to speak relatively openly about the mental deterioration within the Surinamese Creole community.

Nevertheless, some family carers did feel uncomfortable about being seen with their family member who had dementia. This shame in public was primarily related to the behaviour of the person with dementia (aggressive behaviour, for example).

A feeling of shame isn't something that comes only from you. I think that what the person with dementia does ... well ... that makes you ashamed of some of the behaviour. You have people who hit out or kick. Or person with dementias who'll pinch you. Some people can't handle that, and then you do feel ashamed.

(Surinamese Creole, focus group interview)

\section{The importance of talking about dementia}

Despite the shame, feelings of unease and the 'culture of silence' mentioned in some cases, the family carers who were interviewed stated that it was important to be able to talk about the illness openly. One reason was that they thought their wider community should know more about dementia. The family carers of Moroccan or Turkish descent in particular said that little was known about the condition in their 
Wezel, N. van, Francke, A.L., Acun, E.K., Devillé, W.L.J.M., Grondelle, N.J. van, Blom, M.M. Explanatory models and openness about dementia in migrant communities: a qualitative study among

female family carers. Dementia: International Journal of Social Research and Practice: 2016

communities. They therefore wanted to tell other people about the illness of their parent, parent-in-law or other relative with dementia.

Communication with other Turkish and Moroccan family carers about dementia was also important for them, allowing them to provide emotional support for one another. Some Turkish and Moroccan caregivers also said that the dementia of their relative would be better accepted and that there would be more understanding and less prejudice if other people knew that it was a common illness.

But I do think it's important to be able to talk about it easily. The more I talk about it with people and the more you give them information, then you start noticing them saying 'Oh, that's in my family too, I've got a grandmother like that too, or an uncle . . . so she's not going mad.' So that makes it easier for me to keep talking about it. The people ... it's an open subject ... yes, making it something you can talk about freely, so that people can learn something from you.

And vice versa. Because it's good when you hear another Moroccan saying that their mother has got the same problem. You've then got feelings that you can share. (Turkish, individual interview) We have to talk about dementia and provide information. The imam in the mosque should provide information. Make the community aware of it. So that others get to know about it. So that people will talk about it and overcome the shame. And they won't stick the 'mad' label on people any more then either. (Moroccan, focus group interview) The family carers of Surinamese Creole descent also thought it important to speak openly about dementia. However, since they were able to talk openly about the disease within their community, they were less explicit compared to the Moroccan and Turkish caregivers about stating the importance of open communication about dementia.

\section{DISCUSSION}

\section{Female family carers from the Turkish, Moroccan or Surinamese Creole} communities generally talk openly with their close family about dementia (which the caregivers often called "forgetfulness") and they also think this is very important. The taboo around the subject of dementia, as has been described in other studies among non-western populations (inter alia Papadopulos et al., 2002; Rijkers, 2010; Wolff et al., 1996) was less pronounced in our study. It was not so much a question of a taboo as feelings of unease and shame - primarily perceived by informal caregivers from the Turkish and Moroccan communities. It is possible that this reflects progress over the course of time: most of the studies referring to 'taboos' were carried out years ago and family carers nowadays (largely second generation immigrants) are possibly more integrated into Dutch society. Therefore, they might have adopted aspects of the 'host culture' (Botsford et al., 2011), and 'cultural exchange' might have taken place (Kottak, 2005), resulting in taking over aspects of the open communication style of the general Dutch population. Another explanation could be that the ageing population means that people within their own communities are increasingly being faced with dementia. There is also a great deal of attention from the media and many informational programmes about dementia, which will also have increased openness in discussing the subject. It is noteworthy here that, despite their own openness about discussing the dementia of their close relatives, the family carers interviewed generally used other names for the condition than those employed 
Wezel, N. van, Francke, A.L., Acun, E.K., Devillé, W.L.J.M., Grondelle, N.J. van, Blom, M.M. Explanatory models and openness about dementia in migrant communities: a qualitative study among

female family carers. Dementia: International Journal of Social Research and Practice: 2016

in the Western healthcare sector, 'dementia' or 'Alzheimer's disease'. Studies carried out by Hinton et al. (2005) have shown comparable results.

However, talking about dementia outside the immediate family circle is still often difficult for family carers with Turkish or Moroccan backgrounds. They point out that the mental deterioration of the person with dementia is something that more elderly members of their communities in particular do not like facing up to.

Communication issues are exacerbated by fear, shame, lack of awareness and uncertainty, not so much among the family carers interviewed themselves but rather among other members of the Turkish and Moroccan communities. The study by De Vries (2009) also clearly highlights that shame and fear within the community. Also 'public stigma' (Benbow \& Reynolds, 2000; Corrigan \& Watson, 2002; Graham et al., 2003; Werner \& Heinik, 2008), still appear to be a problem, since some family carers indicated that they see it as their task to refute in their communities beliefs such as dementia is a form of 'madness' or 'possession'. Stigma, anxiety and shame associated with dementia have a negative impact on how freely it can be discussed when dementia is seen as a 'spiritual experience', in the sense of possession or magic. If a person with dementia is seen as someone who is possessed or under the influence of black magic, this might go hand in hand with gossip in the community and shame within the family, which will also inhibit communication about dementia. Themes such as shame, fear and a bar against discussion of dementia within the community play less of a role in the experiences of Surinamese Creole family carers than in those with Turkish or Moroccan backgrounds. Possible explanations for this can be found in the cultural 'proximity' to Dutch society, education and the degree of integration. Firstgeneration immigrants from Suriname are on average better educated, speak Dutch better and are more familiar with the Dutch healthcare system than Turkish or Moroccans living in The Netherlands (Denktas, 2011). Another explanation is that they are more familiar with dementia because their average age is greater than in the Turkish and Moroccan groups, so they have been confronted with dementia more. Based on those differences, it is possible to explain why informal caregivers from the Surinamese Creole community are able to talk more freely about dementia with other people from that community.

It is also noteworthy that the dominant explanatory model in Western healthcare ('dementia as a neuropsychiatric condition') was not widely adopted by the family carers interviewed. The explanations given by family carers in our study were often in line with what Downs et al. (2006) describe as the explanatory models of 'dementia as a normal ageing process 'or 'dementia as a spiritual experience'. In addition, some family carers explained dementia as the interplay between various factors (personality traits, psychosocial and physical factors). These findings are in line with Hinton et al. (2005), who also showed that representatives of non-western minority groups often explain dementia outside the dominant medical model of Western societies.

Downs et al. (2006) also listed the explanatory model of 'dementia as an interplay of factors. However, the explanations given by the family carers in our study do not fit this entirely, because the physical factors mentioned in our study are not the progressive brain disorder (where Downs et al., 2006), but other physical factors (such as dehydration or certain medicines) that have nothing to do with dementia when seen from the perspective of Western medicine. 
Wezel, N. van, Francke, A.L., Acun, E.K., Devillé, W.L.J.M., Grondelle, N.J. van, Blom, M.M. Explanatory models and openness about dementia in migrant communities: a qualitative study among

female family carers. Dementia: International Journal of Social Research and Practice: 2016

Regarding the explanation of dementia as a 'a normal ageing process', the most< frequent variant in this study, Downs et al. (2006) state that this explanation doesviotel have a negative impact on the status of the person with dementia. The honour and respect owed to the close relative who has dementia then remain intact; after all, it is only due to their advanced age and nobody can do anything about that. The explanation that 'dementia is an interplay between life events, personality traits and social and psychological factors' also does not seem to have a direct negative impact on the relative with dementia. After all, this does treat the individual person with dementia as a unique person for whom the support and supervision has a chance of succeeding if it focuses on the psychological and social factors and life events that underpin the dementia, rather than the general medical explanation. This was also found in a study carried out by Bagley, Angel, Dilworth-Anderson, Liu, and Schinke (1995).

\section{Strengths, limitations and recommendation for future research}

One of the strong points of this study is that it used both individual interviews and focus groups. Individual interviews have the advantage of allowing in-depth questions about

personal and individual experiences, which generates rich and detailed information. Focus group discussions have the advantage of allowing scope for discussion and exchange of ideas amongst those taking part. The individual interviews and the focus groups have reinforced and complemented each other. One finding that was highlighted strongly in the focus groups and provided further backing for the findings from the individual interviews, for instance, was that the often uncomfortable openness to discussion of dementia within the wider community is primarily founded on fear of the condition and lack of awareness of it among other members of that community, as well as fear of gossip about the immediate family members of the person with dementia.

One limitation of this study is that it only involved family carers from non-western communities in the Netherlands and no native Dutch caregivers. When interpreting the study's results and conclusions, allowances should also be made for the fact that there is diversity within communities too and that the Surinamese family carers we interviewed were all ethnically Creoles. It is possible that some aspects of the results obtained might not apply to family carers from other Surinamese communities, such as the Surinamese-Hindustani- or Surinamese Chinese-communities in The Netherlands.

We must also take account of the fact that this study did not involve native Dutch family carers, although not only the cultural or ethnic background but also aspects like education, social networks, income or duration of contacts with health systems might be related to explanatory models and openness to discuss dementia within others. Therefore, we recommend future comparative research also involving native family carers.

Another (obvious) limitation is that this study only included informal caregivers who themselves were willing and able to talk openly about their close relative's dementia. Family carers who have difficulty talking about dementia or found discussing the subject inappropriate for other reasons will of course not have wanted to be interviewed. The observation that the informal caregivers interviewed wanted to talk openly and also see it as their task to make dementia a topic that can be discussed more freely in their community can therefore not automatically be generalized to 
Wezel, N. van, Francke, A.L., Acun, E.K., Devillé, W.L.J.M., Grondelle, N.J. van, Blom, M.M. Explanatory models and openness about dementia in migrant communities: a qualitative study among

female family carers. Dementia: International Journal of Social Research and Practice: 2016

other caregivers from the community in question. Furthermore, previous researeh has shown that ethnic background appears to account for differences in experiences $\phi f i v e l$ dementia and caregiving, but that other compounding variables, including socioeconomic factors and education, also need to be taken into account when considering the experiences of specific ethnic communities (Botsford et al., 2011).

Finally, an explanatory model reveals how people make sense of their illness and their experiences of it. They perceive are used to explain how people view their illness in terms of how it happens, what causes it, how it affects them, and what will make them feel better (Kleinman, 1976). We did not focus on the explanatory models of people with dementia themselves, but we only focused on how family carers explain the origin of the disease and how it affects them in the sense of communicating about dementia. Further research is recommended on how people with (early) dementia in non-western communities make sense of their disease and how they experience it as illness.

\section{Recommendations}

Special interest groups for dementia - such as the national Alzheimer Associations are currently making major efforts to provide culture-specific information about dementia.

There is an assumption here that it is important not only to pay attention to increasing people's knowledge about dementia, but also to make the disease a subject that can be more freely discussed. Among the family carers interviewed for this study, it was very clear that they themselves also value open communication about dementia very highly, both within their families and in the community at large. Nevertheless, these family carers do also point out that there are still barriers within the Turkish and Moroccan communities against talking openly about dementia. These barriers seem partly to be associated with explanations of dementia such as 'this condition is due to them being possessed' or that they 'have a difficult personality'. These barriers can however also be due to the way people look at communicating about sensitive subjects. People producing information about dementia should allow for the fact that not everyone will necessarily subscribe to the idea that talking freely about dementia is a good idea or that perceiving dementia within the dominant western 'normalizing' explanatory model automatically means that there is enough capacity and agency to cope with the disease or that family carers are better off. In light of the growing number of people with dementia and family carers it may therefore be worthwhile to make use of trained information providers from the same non-western origins as the target groups, who know about the causes and symptoms of dementia and who themselves have experience as family carers. Information providers with the same language and culture, may be able to build bridges between these partially culturally determined explanations of dementia, at the same time paying attention to filling in the gaps in people's knowledge about dementia. These information providers can also function as role models in communication about dementia in Turkish, Moroccan and Surinamese-Creole communities. This might also increase the openness on dementia.

Informational programmes have now been developed for dementia that focus specifically on the groups of informal caregivers with a Turkish, Moroccan or Surinamese background (Blom \& Willemsen, 2011; Willemsen \& van Wezel, 2011). It is therefore important to investigate whether these specific informational programmes do improve knowledge about dementia and openness to discussion. 
Wezel, N. van, Francke, A.L., Acun, E.K., Devillé, W.L.J.M., Grondelle, N.J. van, Blom, M.M. Explanatory models and openness about dementia in migrant communities: a qualitative study among

female family carers. Dementia: International Journal of Social Research and Practice: 2016

\section{Acknowledgements}

We thank all Turkish, Moroccan and Surinamese-Creole family carers who $\frac{\text { niver }}{2016}$ participated in this study.

Furthermore we thank all the trained interviewers for their contribution to this study.

\section{Authors' contributions}

$\mathrm{NvW}$ conceived and designed the study. AFr and MB adjusted the study design and MB obtained funding. NvW drafted the manuscript and coordinated the data collection. The individual interviews were held by NvW and EK. The six focus group interviews were held by EK and NvG. All authors have been involved in revising the manuscript. All authors read and approved the final manuscript.

\section{Declaration of conflicting interests}

The author(s) declared no potential conflicts of interest with respect to the research, authorship, and/or publication of this article.

\section{Funding}

The author(s) disclosed receipt of the following financial support for the research, authorship, and/or publication of this article: 'Alzheimer Nederland'.

\section{REFERENCES}

Adelman, S., Blanchard, M., \& Livingstone, G. (2009). A systematic review of the prevalence and covariates of dementia or relative cognitive impairment in the older African-Caribbean population in Britain. International Journal of Geriatric Psychiatry, 24, 657-665.

Alzheimer's Disease International (ADI). (2012). World Alzheimer report 2012: Overcoming the stigma of dementia. London: ADI.

Alzheimer Nederland. (2013). Factsheet: Cijfers en feiten over dementie en allochtonen. Amersfoort: Alzheimer Nederland.

Ayalon, L., \& Arean, P. (2004). Knowledge of Alzheimer's disease in four ethnic groups of older adults. International Journal of Geriatric Psychiatry, 19, 51-57.

Bagley, S. P., Angel, R., Dilworth-Anderson, P., Liu, W., \& Schinke, S. (1995). Panel V. Adaptive health behaviours among ethnic minorities. Health Psychology, 14, 632-640.

Benbow, S. M., \& Reynolds, D. (2000). Challenging the stigma of Alzheimer's Disease. Hospital Medicine, 61, 174-177.

Blom, M., \& Willemsen, M. N. (2011). Het Alzheimer Theehuis voor Turkse en Marokkaanse mensen met dementia. Denkbeeld, 3, 29.

Botsford, J., Clarke, C. L., \& Gibb, C. E. (2011). Research and dementia, caring and ethnicity: A review of the literature. Journal of Research in Nursing, 16(5), 437-449. Byetheway, B. (1994). Ageism. Buckingham: Open University Press.

Caelli, K., Ray, L., \& Mill, J. (2003). 'Clear as mud': Toward greater clarity in generic qualitative research. International Journal of Qualitative Methods, 2(2), 1-24.

Cohen, L. (1992).No aging in India: The uses of gerontology. Cultural Medical Psychiatry, 16(2), 123-161.

Corrigan, P. W., \& Watson, A. C. (2002). The paradox of self-stigma and mental illness. Clinical Psychology-Science \& Practice, 9, 35-53.

Crossley, M. L. (2000). Rethinking health psychology. Buckingham: Open University Press.

De Graaff, F. M., Francke, A. L., van den Muijsenbergh, M. E. T. C., \& Van der Geest, S. (2010).

Palliative care: A contradiction in terms? A qualitative study of cancer patients with a Turkish or Moroccan background, their relatives and care providers. BMC Palliative Care, (9), 19.

De Graaff, F. M., \& Francke, A. L. (2003). Home care for terminally ill Turks and Moroccans and their families in the Netherlands: carers' experiences and factors influencing ease of access and use of services. International Journal of Nurings Studies, 40, 797-805.

De Vries, I. (2009). Bunamak: Oud of ziek? Dementie en zorg bij oudere Turkse migranten in Amsterdam. Medische Antropologie, 21(1), 117-130. 
Wezel, N. van, Francke, A.L., Acun, E.K., Devillé, W.L.J.M., Grondelle, N.J. van, Blom, M.M. Explanatory models and openness about dementia in migrant communities: a qualitative study among

female family carers. Dementia: International Journal of Social Research and Practice: 2016

Demirovic, J., Prineas, R., Loewenstein, D., Bean, J., Duara, R., Sevush, S., . . Szapeeznik, J. (2003).

Prevalence of dementia in three ethnic groups: The South Florida program on aging and health.

Annals of Epidemiology, 13, 472-478.

Denktas, S., Koopmans, G., Birnie, E., Foets, M., \& Bonsel, G. (2009). Ethnic background and differences in health care use: A national cross-sectional study of native Dutch and non-western elderly in the Netherlands. International Journal for Equity in Health, 8, 35-43.

Denktas, S. (2011). Health and healthcare use of elderly non-westerns in the Netherlands. A comparative study. PhD Thesis, Erasmus University Rotterdam.

Dijkstra, S., Berghout, A., \& Sauerwein, H. P. (2003). Prevalence of diabetes mellitus and cardiovascular disease among non-westerns from Turkey and Morocco and the indigenous Dutch population. Nederlands tijdschrift voor geneeskunde, 147(43), 2146-2147.

Downs, M., Clare, L., \& Mackenzie, J. (2006). Understandings of dementia: Explanatory models and their implications for the person with dementia and therapeutic effort.

Dementia, Mind, Meaning and the Person, 234-258.

Engel, G. L. (1997). The need for a new medical model: A challenge for biomedicine. Science, 196, 129-136.

Fitzpatrick, A. L., Kuller, L. H., Ives, D. G., Lopez, O. L., Jagust, W., Breitner, J. C. S., . . . Dulberg, C. (2004). Incidence and prevalence of dementia in the Cardiovascular Health Study. Journal of the American Geriatrics Society, 52, 195-204.

Forouhi, N. G., Merrick, D., Goyder, E., Ferguson, B. A., Abbas, J., Lachowycz, K., . . Wild, S. H.

(2006). Diabetes prevalence in England, 2001 - Estimates from an epidemiological model. Diabetic Medicine, 23, 189-197.

Gary, F. A. (2005). Stigma: Barrier to mental health care among ethnic minorities. Issues in Mental Health Nursing, 26, 979-999.

Graham, N., Lindesay, J., Katona, C., Bertolote, J. M., Camus, V., Copeland, J. R., . . Wancata, J.

(2003). Reducing stigma and discrimination against older people with mental disorders; A technical consensus statement. International Journal of Getriatric Psychiatry, 18, 670-678.

Guest, G. A., Bunce, L., \& Johnson (2006). How many interviews are enough? An experiment with data saturation and variability. Field Methods, 18(1), 59-82.

Headland, T. N., Pike, K. L., \& Harris, M. (Eds). (1990). Emics and etics: The insider/outsider debate.

In Frontiers of anthropology. v. 7. Newbury Park, CA: Sage Publications.

Hinton, L., Franz, C., Yeo, G., \& Levkoff, S. E. (2005). Conceptions of dementia in a multiethnic sample of family caregivers. Journal of the American Geriatrics Society, 53, 14051410.

Hussain, A. (2001). Islamic beliefs and mental health. Mental Health Nursing, 21: 2 and 6-9.

Kitwood, T. (1990). The dialectics of dementia: With particular reference to Alzheimer's disease.

Ageing and Society, 10, 177-196.

Kleinman, A. (1976). Culture, illness and care: Clinical lessons from anthropologic and crosscultural research. Annals of Internal Medicine, 88, 251-258.

Kottak, C. P. (2005). Windows on humanity (pp. 209-423). New York, NY: McGraw Hill.

Marks, D., Murray, M., Evans, B., \& Estacio, E. V. (2005). Health psychology theory, research and practice. London: Sage.

Papadopulos, C., Leavey, G., \& Vincent, C. (2002). Factors influencing stigma: A comparison of Greek-Cypriot and English attitudes towards mental illness in north London. Social Psychiatry and Epidemiology, 37, 430-434.

Reis, R., van der Geest, S., \& Gerrits, T. (2008). Over kwalitatieve analyse bij onderzoek onder 'anderen'.

In M. Foets, J. Schuster, \& K. Stronks (Eds.), Gezondheids(zorg)onderzoek onder allochtone bevolkingsgroepen (NWO-reeks sociale cohesie, 16) (pp. 108-121). Amsterdam: Aksant.

Rijkers, C. (2010). Dementia among elderly Moroccan non-westerns in the Netherlands. Master Thesis, Department of Social Sciences, VU University, Amsterdam. 
Wezel, N. van, Francke, A.L., Acun, E.K., Devillé, W.L.J.M., Grondelle, N.J. van, Blom, M.M.

Explanatory models and openness about dementia in migrant communities: a qualitative study among

female family carers. Dementia: International Journal of Social Research and Practice: 2016

Roberts, J. S., Connell, C. M., Cisewski, D., Hipps, Y. G., Demissie, S., \& Green, R. (2003).

Differences between African Americans and whites in their perceptions of Alzheimers

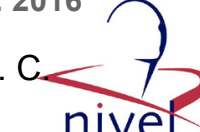
disease.

Alzheimer Disease \& Associated Disorders, 17, 19-26.

Sun, F., Ong, R., \& Burnette, D. (2012). The influence of ethnicity and culture on dementia caregiving: A review of empirical studies on Chinese Americans. American Journal of Alzheimer's Disease \& Other Dementias, 27, 13-22.

Uiters, E., Deville, W. L. J. M., Foets, M., \& Groenewegen, P. P. (2006). Use of health care services by ethnic minorities in the Netherlands: Do patterns differ? The European Journal of Public Health, 16, 388-393.

van Wezel, N., Francke, A. L., Deville' , W. L., Blom, M. M., van Grondelle, N. J., \& KayanAcun, E.

(2014) Family care for immigrants with dementia: The perspectives of female family carers living in the Netherlands. Dementia, 15(1), 69-84.

Werner, P., \& Heinik, J. (2008). Stigma by association and Alzheimers's disease. Aging \& Mental Health, 12(1), 92-99.

Willemsen, M. N., \& van Wezel, N. (2011). Dementie bij oudere migranten. Denkbeeld, 5, 25.

Wolff, G., Pathare, S., Craig, T., \& Leff, J. (1996). Community attitudes to mental illness. British Journal of Psychiatry, 168, 183-190.

Zhan, L. (2004). Caring for family members with Alzheimer's disease: perspectives from Chinese American caregivers. Journal of Gerontology and Nursing, 8, 19-29. 
Wezel, N. van, Francke, A.L., Acun, E.K., Devillé, W.L.J.M., Grondelle, N.J. van, Blom, M.M.

Explanatory models and openness about dementia in migrant communities: a qualitative study among

female family carers. Dementia: International Journal of Social Research and Practice: 2016

TABLES

Table I. Features of the backgrounds of the female family carers interviewed.

\begin{tabular}{|c|c|c|c|}
\hline Group & Age (distribution) & $\begin{array}{l}\text { Lives with a close } \\
\text { relative with dementia? }\end{array}$ & Family relationship \\
\hline \multicolumn{4}{|c|}{ Family carers from the individual interviews $(n=4 I)$} \\
\hline $\begin{array}{l}\text { Turkish } \\
(n=16)\end{array}$ & Distribution $=31-74$ & $\begin{array}{l}\text { Yes: } 6 \\
\text { No: } 10\end{array}$ & $\begin{array}{l}\text { Daughter: I4 } \\
\text { Daughter-in-law: I } \\
\text { Spouse: I }\end{array}$ \\
\hline $\begin{array}{l}\text { Moroccan } \\
(n=14)\end{array}$ & Distribution $=20-48$ & $\begin{array}{l}\text { Yes: } 5 \\
\text { No: } 9\end{array}$ & $\begin{array}{l}\text { Daughter: } 12 \\
\text { Daughter-in-law: } 2 \\
\text { Spouse: } 0\end{array}$ \\
\hline $\begin{array}{l}\text { Surinamese } \\
(n=I I)\end{array}$ & Distribution $=50-84$ & $\begin{array}{l}\text { Yes: I } \\
\text { No: } 10\end{array}$ & $\begin{array}{l}\text { Daughter: } 8 \\
\text { Daughter-in-law: } 2 \\
\text { Spouse: I }\end{array}$ \\
\hline \multicolumn{4}{|c|}{ Female family carers from the focus group interviews $(n=28)$} \\
\hline $\begin{array}{l}\text { Turkish } \\
(n=10)\end{array}$ & Distribution $=30-50$ & $\begin{array}{l}\text { Yes: } 4 \\
\text { No: } 6\end{array}$ & $\begin{array}{l}\text { Daughter: } 10 \\
\text { Daughter-in-law: } 0 \\
\text { Spouse: } 0\end{array}$ \\
\hline $\begin{array}{l}\text { Moroccan } \\
(n=12)\end{array}$ & Distribution $=30-60$ & $\begin{array}{l}\text { Yes: } 5 \\
\text { No: } 7\end{array}$ & $\begin{array}{l}\text { Daughter: } 5 \\
\text { Daughter-in-law: } 4 \\
\text { Spouse: I } \\
\text { Other: } 2\end{array}$ \\
\hline $\begin{array}{l}\text { Surinamese } \\
(n=6)\end{array}$ & Distribution $=30-70$ & $\begin{array}{l}\text { Yes: } 0 \\
\text { No: } 6\end{array}$ & $\begin{array}{l}\text { Daughter: } 6 \\
\text { Daughter-in-law: } 0 \\
\text { Spouse: } 0\end{array}$ \\
\hline
\end{tabular}

